\title{
COMPARING GUIDELINES CONCERNING CONSTRUCTION OF THE S-N CURVE WITHIN LIMITED FATIGUE LIFE RANGE
}

\author{
Przemysław Strzelecki, PhD \\ Janusz Sempruch, Prof. \\ Krzysztof Nowicki, PhD \\ University of Technology and Life Sciences in Bydgoszcz, Poland
}

\begin{abstract}
The article collates guidelines concerning experimental construction of the S-N fatigue curves within a limited fatigue life range. An attempt is made to compare these guidelines, based on experimental data recorded during rotating bending of a notched specimen made of $42 \mathrm{CrMo4}$. The recorded differences in fatigue life values between the constructed curves reach the maximum of $12.2 \%$. According to the above guidelines, the number of tests in particular test series varies from 6 to 28. Based on the performed analysis a conclusion was made that the increase in the number of tests leads to the increase of accuracy but, on the other hand, remarkably increases the time of the experiment and, consequently, its cost. In this context, it is the research worker who, taking into account a possible future use of the fatigue curve, should individually decide about its accuracy.
\end{abstract}

Keywords: high-cycle fatigue, S-N curve, fatigue tests

\section{INTRODUCTION}

When designing new structural elements which are expected to be exposed to time-dependent loads, such as for instance load-bearing parts of ship hulls, their fatigue strength curve is calculated for the assumed lifetime [1]. These calculations require the information on the S-N fatigue characteristic.

For this purpose curves constructed according to normative guidelines [2] or those formulated by classification societies $[3,4]$, for instance, are used. Specimen fatigue curves for different categories of welded joints, taken from [4], are shown in Fig. 1. The recommended characteristics refer to $75 \%$ confidence with $95 \%$ probability of reliability $[2,5]$. It is noteworthy that the dispersion of the results recorded in experimental examination is relatively large, as shown in Fig. 2 [7]. Since any change of material, geometry, heat treatment, etc., of the structural element results in its fatigue strength change, fatigue tests are to be repeated each time when new technology is introduced, or new material used.

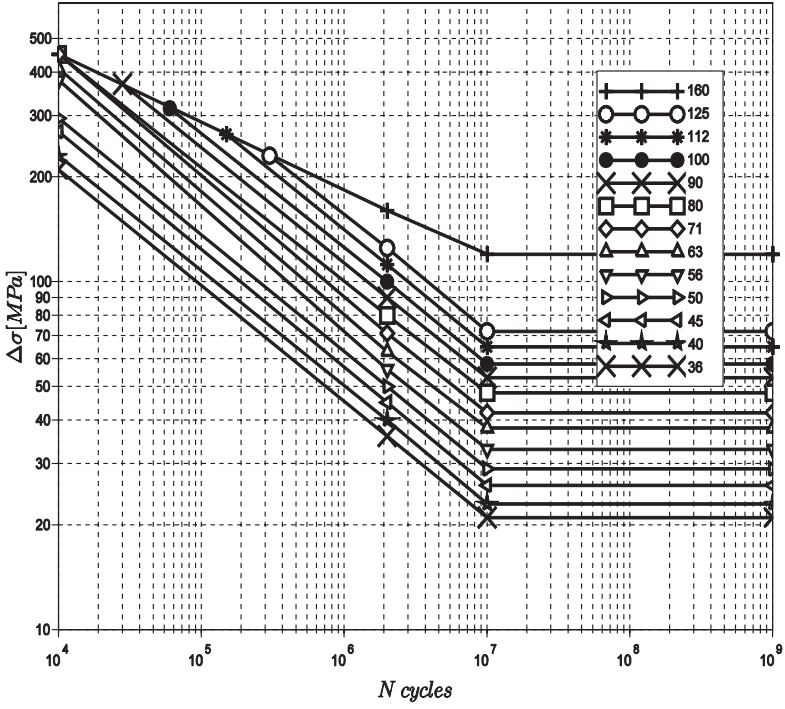

Fig. 1. Specimen fatigue curves for different categories of welded joints [4] 
For instance, Ref. [8] presents the effect of the size of the tested object on its fatigue life.

Fatigue tests oriented on constructing the S-N curve within a limited fatigue life range can be performed based on guidelines given in $[5,6,9,10,11]$, among other options. However, despite the fact that all these documents refer to the limited fatigue life range, each of them was prepared for an individually defined scope of applications and contains different guidelines.

The present analysis aims at comparing these guidelines and presenting experimental verification of the effects of their implementation when constructing the S-N characteristic.

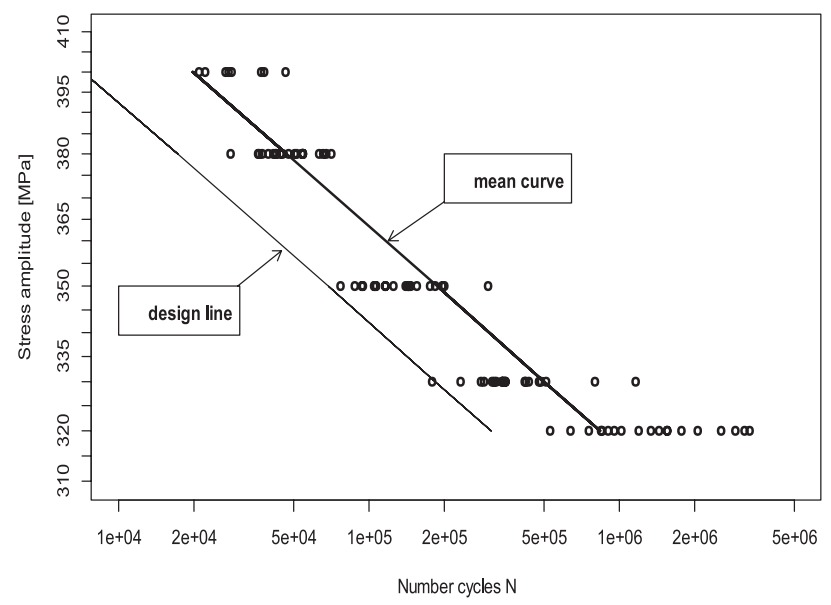

Fig. 2. Dispersion of results of fatigue tests for steel 0,72\%C [7]

\section{NUMBER OF TESTED SPECIMENS}

The fatigue tests are time-consuming and, consequently, expensive. For instance, obtaining 105 cycles at the loading frequency of $30 \mathrm{~Hz}$ takes $55 \mathrm{~min}$, while 106 cycles require as much as 9 hours. This assessment does not take into account the time of specimen preparation. It is also noteworthy that fatigue test machines frequently enable to obtain much lower frequency, for instance $5 \mathrm{~Hz}$ or less, which even more extends the time of examination. That is why numerous research workers limit the number of the tested specimens to a minimum, in particular in case of multiaxial fatigue tests, such as those reported in Ref. [12]. Since different characteristics are frequently used for comparisons, for instance to determine the effect of different production technologies on the fatigue life, numerous normative guidelines were worked out which define the minimal acceptable number of specimens. Selected guidelines are discussed below.

According to the standard [11], tests oriented on determining the fatigue characteristic for a given reliability level, require 28 specimens as the minimum, while in preliminary tests 7 specimens are recommended as sufficient. The above guidelines do not define the number of the applied load levels, they only refer to the standard ASTM [6] which gives the relation for the replication percent:

$$
P R=100\left[1-\left(\frac{S l}{n}\right)\right][\%]
$$

where:

$S l$ - number of load levels,

$n$ - total number of specimens.

This standard includes a suggestion that the replication percent given in Tab. 1 is to be obtained.

It is noteworthy that the minimal number of specimens recommended in the standard [11] is larger than that given in the document [6]. Numbers of specimens suggested in the ASTM standard are given in Tab. 2.

Other guidelines can be found in the EN standard [9], where a proposal is formulated to start the test at the load level for which the fatigue life approximately equal to $10^{5}$ cycles is expected. This guideline can be applied when the characteristic for a similar material is known. When the reliable information which would enable to assess this load level is missing, the following formula can be used instead:

$$
\mathrm{S}_{5}=(\mathrm{UTS}+0.2 \% \mathrm{PS}) / 2 \text {, }
$$

where:

$\mathrm{S}_{5}$ - stress amplitude for 105 cycles

UTS - ultimate tensile strength,

$0.2 \%$ PS - proof stress.

The above notation is in accordance with the document [9]. It is noteworthy that the fatigue life based on tensile test results can be calculated using analytical methods, described in $[13,14]$, among other references.

Tab. 1 Guidelines concerning the replication percent for various tests [6]

\begin{tabular}{|c|c|}
\hline Type of Tests & $\begin{array}{c}\text { Replication } \\
\text { Percent }\end{array}$ \\
\hline $\begin{array}{c}\text { Preliminary and exploratory } \\
\text { (research and development tests) }\end{array}$ & 17 to 33 \\
\hline $\begin{array}{c}\text { Research and development tests of } \\
\text { components and specimens }\end{array}$ & 33 to 50 \\
\hline Design allowable data & 50 to 75 \\
\hline Reliability data & 75 to 88 \\
\hline
\end{tabular}

Tab. 2 Guidelines concerning the number of specimens [6]

\begin{tabular}{|c|c|}
\hline Type of Test & $\begin{array}{c}\text { Minimum } \\
\text { number of } \\
\text { specimens }\end{array}$ \\
\hline $\begin{array}{c}\text { Preliminary and exploratory } \\
\text { (research and development tests) }\end{array}$ & 6 to 12 \\
\hline $\begin{array}{c}\text { Research and development tests } \\
\text { of components and specimens }\end{array}$ & 6 to 12 \\
\hline Design allowable data & 12 to 24 \\
\hline Reliability data & 12 to 24 \\
\hline
\end{tabular}


The next level of load should be lower by $40 \mathrm{MPa}$ than the initial level. If the specimen cracks before the number of $10^{7}$ cycles is obtained, the next level of load should be decreased by $20 \mathrm{MPa}$. Then, the level of load should be increased by $40 \mathrm{MPa}$ with respect to the initial level. If the specimen does not crack after about $10^{4}$ cycles, the level of load should be increased by the next $20 \mathrm{MPa}$. As a final part, tests should be performed for the load levels situated between those previously applied. This testing procedure does not include the information on the recommended minimal number of specimens.

Other guidelines can be found in the PN standard [10]. This document recommends that the tests are to be performed for a minimum of 15 specimens and at least for 5 levels of load. The obtained S-N characteristic should cover the range from $10^{4}$ to $10^{6}$ cycles.

On the other hand, the guidelines of the International Institute of Welding [5] suggest that the tests are to be performed for a minimum of 10 specimens, and for at least 2 levels of load within the range from $10^{5}$ to $10^{6}$ cycles.

It is also noteworthy that the ISO standard [11] has the applicability range limited to determining fatigue properties of metal elements, while the ASTM document [6] refers generally to construction of the S-N curve when it can be estimated using linear regression for the probability not lower than $5 \%$.

In turn, the EN standard [9] can be applied for metal materials for which high-cycle fatigue characteristics are to be constructed. It does not refers clearly to structural elements, but only suggests that this methodology can be applied for those elements.

The PN standard [10] refers to tests of metals at axial load, bending, and twisting. It can be used for both smooth and notched specimens. The above standard does not include tests of specimens with welded, or glued joints, etc.

The IIW document [5] is recommended in cases of tests of welded elements made of steel or aluminium.

\section{INTERVAL BETWEEN LOAD LEVELS}

As shown in Ref. [15], the S-N characteristic can take different forms. Within the limited fatigue life range it can be most frequently estimated by a linear model, see Fig. 3 . This model of S-N characteristic is applied in the majority of practically used methods to calculate limited fatigue life and strength within this cycle range. Fig. 3 shows a scheme of estimation of the fatigue characteristic based on experimental data. The relation between the fatigue life and the load is most frequently estimated using the linear regression method, which can be described as:

$$
\log (N)=m \log (S)+b,
$$

where:

$m$ - slope coefficient,

$b$ - intercept term.

The values of the slope coefficient $m$ vary within a wide range (Fig. 5, Fig. 6, Fig. 7, Fig. 8). When the value of $m$ is close to the upper limit of its changeability, the characteristic becomes more horizontal and the intervals between the levels of load become smaller. On the other hand, when the slope coefficient $m$ is small, the fatigue characteristic has a more vertical form and, consequently, the intervals between the levels of load are larger. As an example, Fig. 4 shows two fatigue characteristics for smooth specimens made of steels 4140 [16] and SUJ2 [17]. The S-N curves for these two materials have different slope coefficients, equal to 23.15 and 9.829 for the former and latter material, respectively. For the material 4140 the fatigue strength changes by about $30 \mathrm{MPa}$ within the cycle number ranging from $5 \cdot 10^{4}$ to $2 \cdot 10^{5}$ cycles. For the steel SUJ 2 and the same cycle range, the stress amplitude is higher and approximately equal to $100 \mathrm{MPa}$.

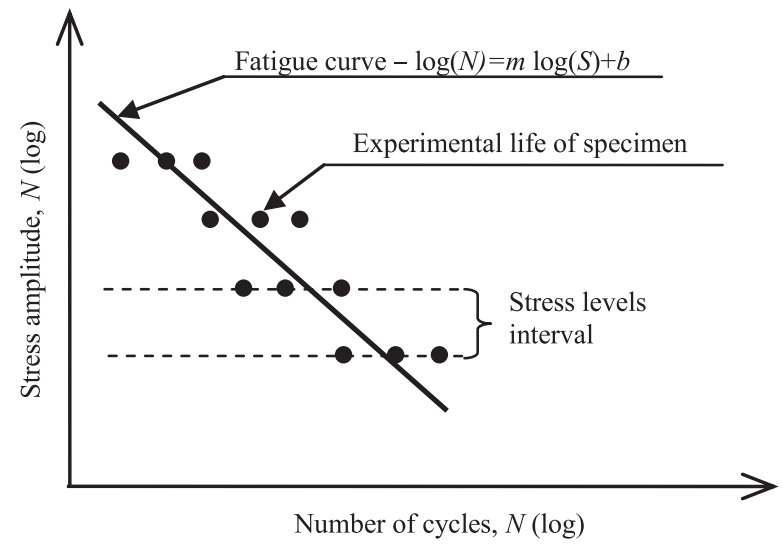

Fig. 3. Scheme of estimating the fatigue curve in high cycle range

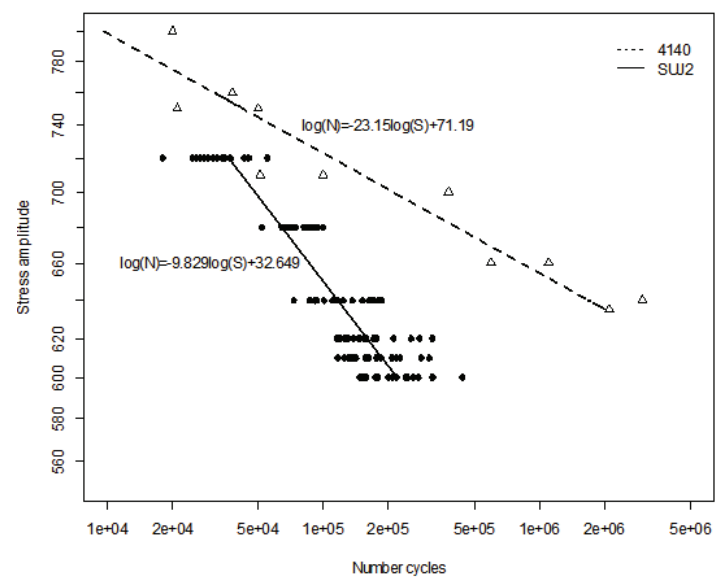

Fig. 4. Fatigue characteristic for steel 4140 [16] and steel SUJ2 [17]

This effect poses a problem when formulating the fatigue test programme, as precise assessment of the next level of load is not possible. To solve this problem, an attempt can be made to assess the most likely value of the coefficient $m$ which will enable to determine approximately the changeability of the fatigue strength within the given range of fatigue life. Analyses oriented on determining slope coefficient changes are presented in $[18,19]$. Fig. 5, Fig. 6, Fig. 7 and Fig. 8 show 
distributions of values of the slope coefficient $m$ for structural steel and normal and shear stresses, and for even and notched specimens.

Fig. 5 reveals that the most frequent value of the slope coefficient $\mathrm{m}$ for smooth specimens and normal stresses is 10.9 , i.e. the value which is higher than that obtained for the material SUJ2, but lower than that for 4140 .

Moreover, it should be noted that in case of notched specimens the dispersion of values of the slope coefficient $\mathrm{m}$ is smaller, which makes assessing intervals between load levels during examination less problematic and more predictable.

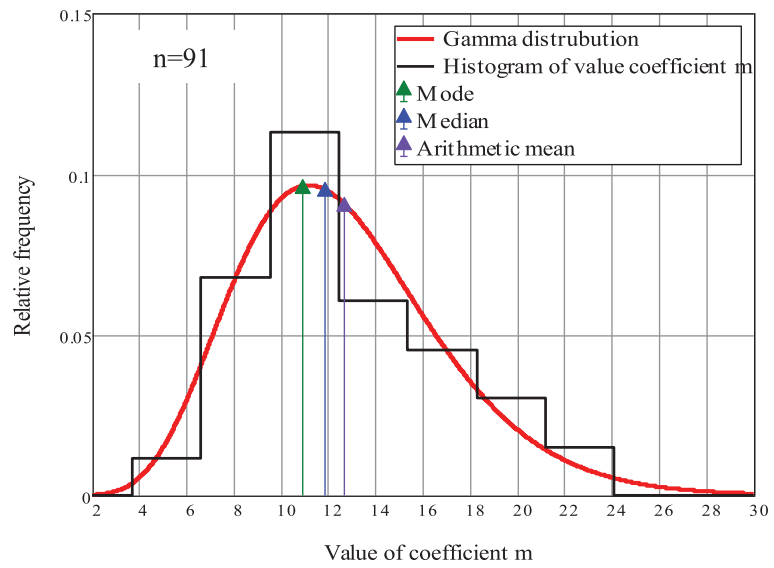

Fig. 5. Distribution of coefficient $m$ for structural steel, smooth specimen, and normal stress

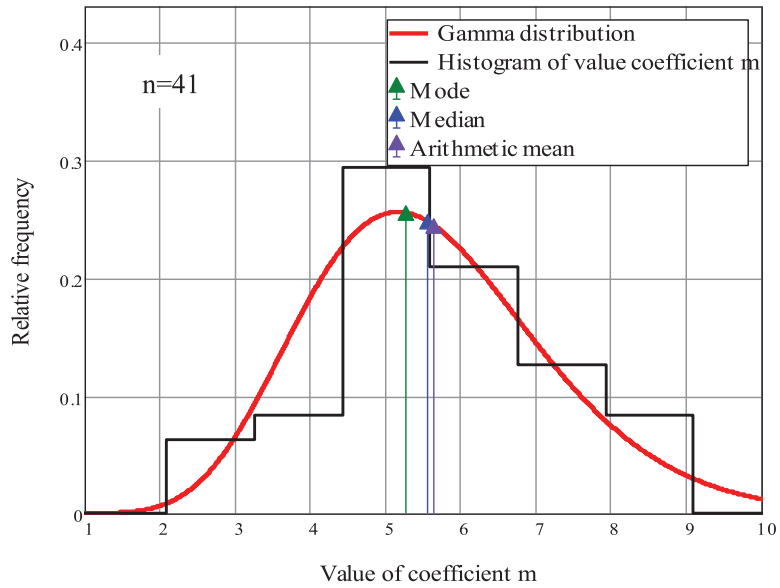

Fig. 6. Distribution of coefficient $m$ for structural steel, notched specimen, and normal stress

The analysis of values of the slope coefficients $m$ has made the basis for calculating modal values of this quantity for selected types of loads and specimens. The results of these calculations are given in Tab. 3, which also includes the calculated strength changes for the fatigue life ranging from $5 \cdot 10^{4}$ to $2 \cdot 10^{5}$ cycles, assuming that the value of the slope coefficient $\mathrm{m}$ is equal to the modal value of the relevant distribution. It is noteworthy that the values obtained for shear stresses and notched specimens have poorer statistical background due to a relatively small amount of data used to construct a histogram (reports on this type of research are under-represented in the literature).

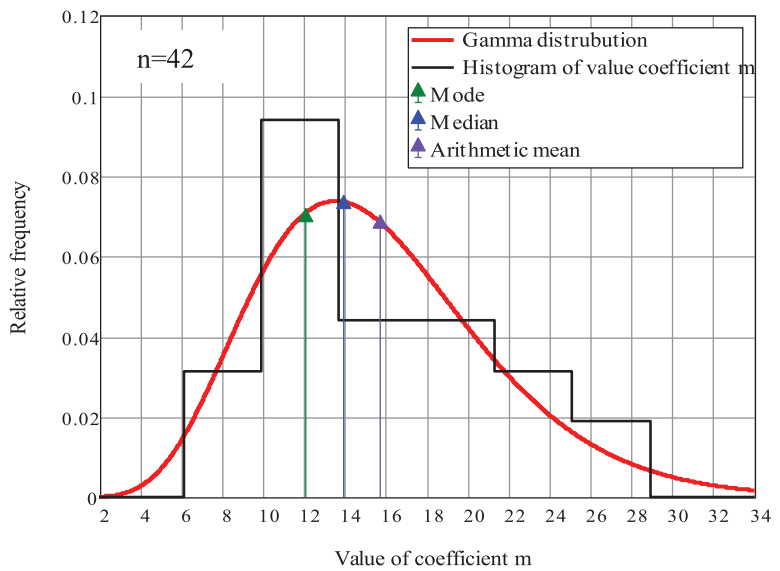

Fig. 7. Distribution of coefficient $m$ for structural steel, smooth specimen, and shear stress

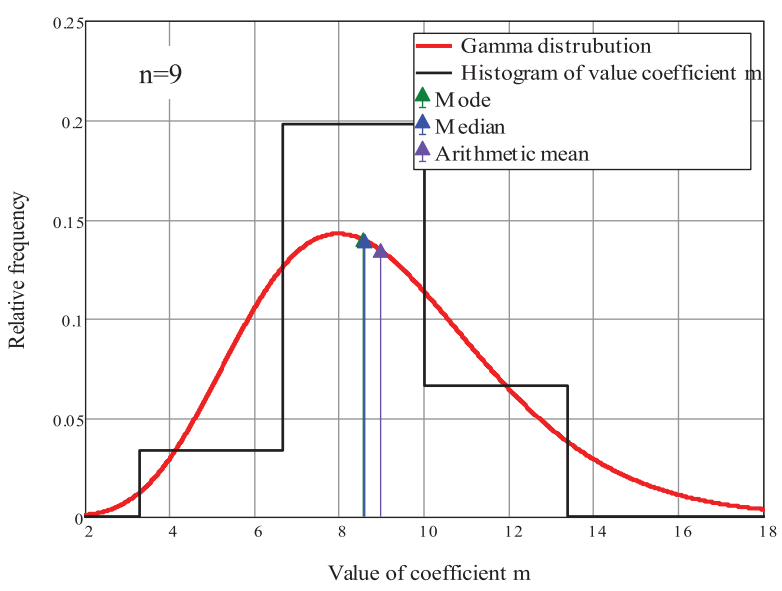

Fig. 8. Distribution of coefficient $m$ for structural steel, notched specimen, and shear stress

Tab. 3 Modal values of slope coefficient $m$ for structural steel

\begin{tabular}{|c|c|c|}
\hline $\begin{array}{c}\text { Type of load and } \\
\text { specimen geometry }\end{array}$ & $\begin{array}{c}\text { Modal value } \\
\text { of slope } \\
\text { coefficient } m\end{array}$ & $\begin{array}{c}\text { Strength change } \\
\text { within fatigue } \\
\text { life ranging from } \\
5 \cdot 10^{4} \text { to } 2 \cdot 10^{5} \\
\text { cycles [MPa] }\end{array}$ \\
\hline $\begin{array}{c}\text { Normal stress } \\
\text { smooth specimens }\end{array}$ & 10.9 & 38 \\
\hline $\begin{array}{c}\text { Normal stress } \\
\text { notched specimens }\end{array}$ & 5.3 & 92 \\
\hline $\begin{array}{c}\text { Shear stress } \\
\text { smooth specimens }\end{array}$ & 12 & 25 \\
\hline $\begin{array}{c}\text { Shear stress } \\
\text { notched specimens }\end{array}$ & 8.5 & 45 \\
\hline
\end{tabular}




\section{EXPERIMENTAL VERIFICATION OF THE PRESENTED GUIDELINES}

The reported tests aimed at, among other goals, obtaining experimentally verified data constructed in accordance with particular guidelines $[5,6,9,10,11]$ and in comparable test conditions, i.e. for the same specimens (Fig. 9), the same material (Tab. 4), and the same type of load (rotating bending, the same strength testing machine).

The tests were performed for the material $42 \mathrm{CrMo} 4$, tempered, and for cylindrical notched specimens. Static properties of the material selected for examination are given in Tab. 4, while the geometry of the specimens is shown in Fig. 9.

Tab. 4 Properties of material $42 \mathrm{CrMo} 4$

\begin{tabular}{|c|c|}
\hline Ultimate strength $\mathrm{S}_{\mathrm{u}}[\mathrm{MPa}]$ & 1172 \\
\hline Yield stress $\mathrm{S}_{\mathrm{y}}[\mathrm{MPa}]$ & 1095 \\
\hline Hardness HB & 308 \\
\hline
\end{tabular}

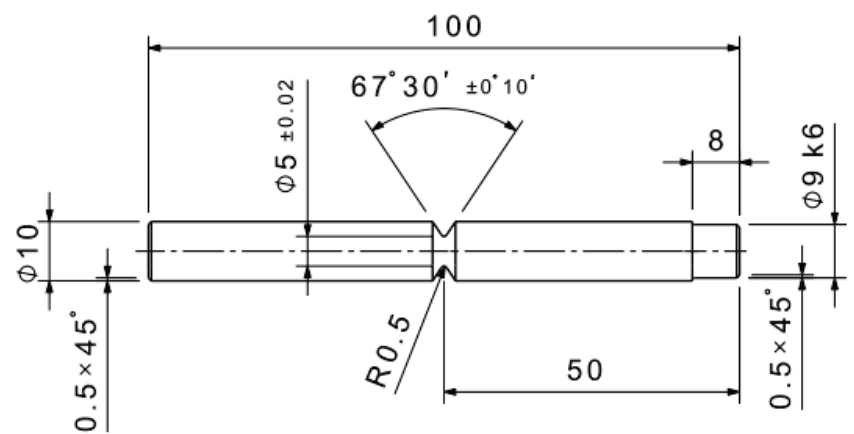

Fig. 9. Notched specimen used for tests

The tests were performed on the research rig used for rotating bending. The strength testing machine and its verification are described in Ref. [20]. The tests were performed at the frequency equal to $28.5 \mathrm{~Hz}$.

The obtained test results are shown in Fig. 10, Fig. 11, Fig. 12 and Fig. 13, along with the estimated S-N curves. The curves were constructed in accordance with the guidelines formulated in the above quoted documents.

In cases when the linear regression was applied to the results shown in Fig. 11 (IIW guidelines [5]), low coefficient of determination and small intervals between load levels were obtained. Moreover, the resultant slope coefficient $m$ differs much from those obtained for the remaining characteristics. It was equal to 6.197 in tests based on IIW guidelines [5], while its values for the remaining characteristics were, respectively, equal to: ISO [11] - 5.809, EN [9] - 5.563, and PN [10] 5.768. The value of the intercept term calculated for the characteristic constructed based on the IIW guidelines [5] is also remarkably higher that the remaining estimated values, which most likely results from the fact that the inflection point of the fatigue characteristic curve is situated close to $4 \cdot 10^{5}$ cycles, which made fatigue life assessment in the vicinity of $10^{6}$ cycles impossible. It is worth mentioning here that Sonsino [21] suggests that the inflection point cycle number of the S-N curve for high-strength steels is equal to $5 \cdot 10^{5}$. The above facts were the reason why the characteristic obtained in accordance with the IIW guidelines [5] was not taken into account in further analysis.

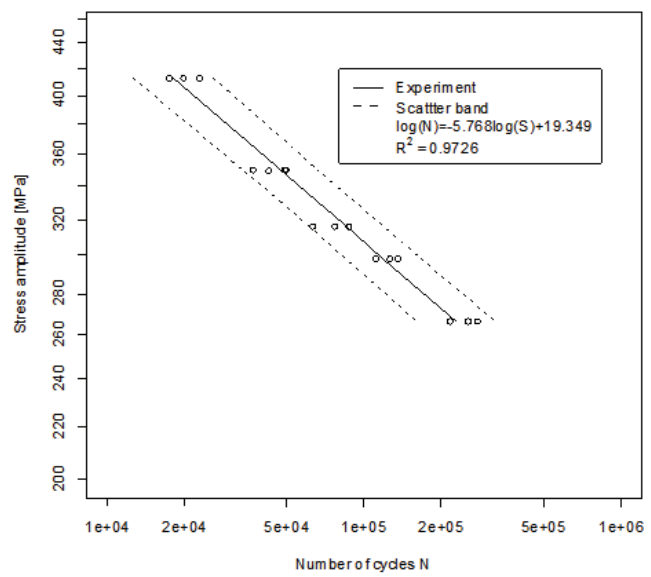

Fig. 10. Fatigue curve of steel $42 \mathrm{CrMo} 4$ for notched specimens, $K_{t}=1.99,[10]$

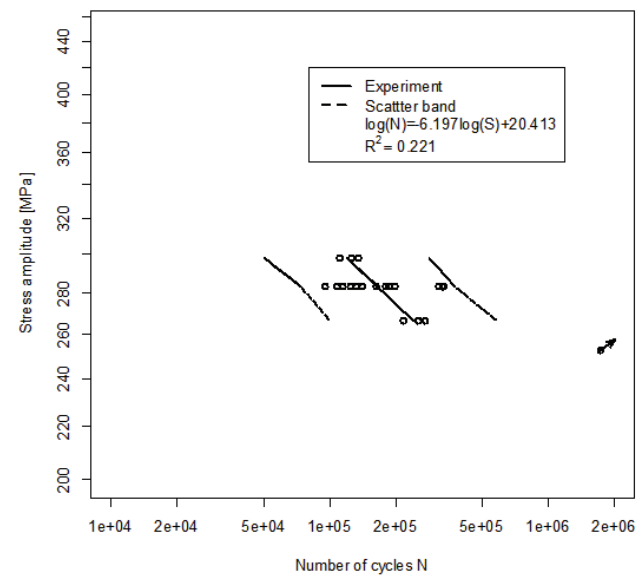

Fig. 11. Fatigue curve of steel 42CrMo4 for notched specimens, $K_{t=1.99,[5]}$

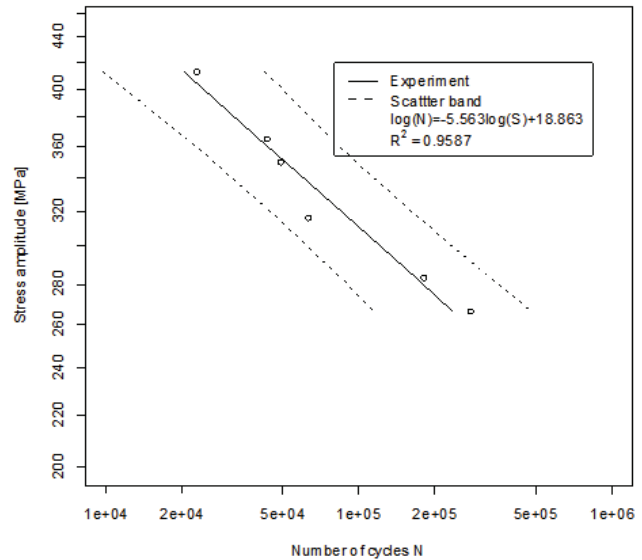

Fig. 12. Fatigue curve of steel 42CrMo4 for notched specimens, $K_{t=1.99,[9]}$ 
Fig. 14 compares all constructed characteristics (except that making use of the IIW methodology [5]). The qualitative analysis reveals that the obtained differences between positions of particular lines are small.

The quantitative comparison was done using the following equation:

$$
B=\frac{N_{1}-N_{2}}{N_{1}} \cdot 100 \%
$$

where:

$B$ - relative difference between the analysed curves,

$N_{1}, N_{2}$ - fatigue life values calculated using the analysed curve.

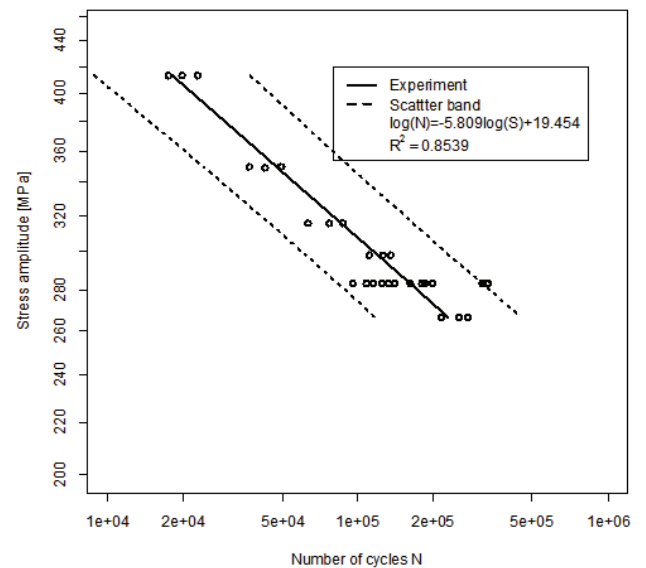

Fig. 13. Fatigue curve of steel 42CrMo4 for notched specimens, $K_{t=1.99,[11]}$

The results calculated using the equation (4) are shown in Fig. 15. The largest difference amounts to $12.2 \%$ and refers to the results obtained bases on PN and EN guidelines. The smallest difference is $-2.6 \%$ and was recorded between the $\mathrm{S}-\mathrm{N}$ curves constructed based on PN and ISO guidelines. The differences between the linear regression coefficients estimated based on the PN and ISO standards were smaller than those based on the PN and EN standards, and the ISO and EN standards.

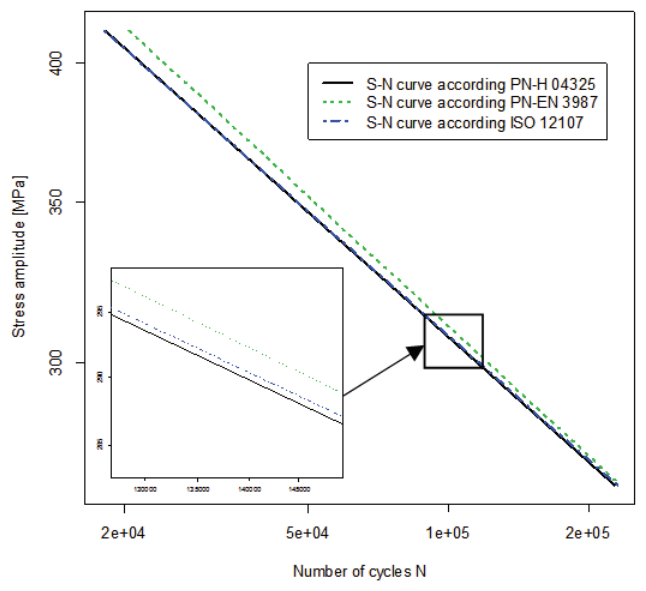

Fig. 14. Comparing the estimated curves

The slope coefficients $\mathrm{m}$ calculated in accordance with the guidelines of ISO [11], EN [9], PN [10] are close to the modal value of 5.27 obtained from the probability function shown in Fig. 6 . At the same time, the stress change amplitude within the fatigue life range from $5 \cdot 10^{4}$ to $2 \cdot 10^{5}$ cycles was smaller and equal to $74 \mathrm{MPa}$.

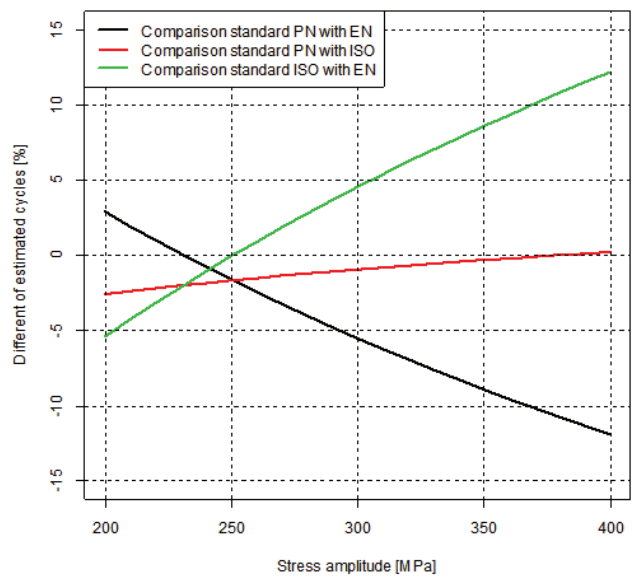

Fig. 15. Differences in cycle estimation based on the obtained fatigue curves for steel 42CrMo4 and notched specimens

\section{SUMMARY AND CONCLUSIONS}

Based on the above analysis of methods to construct the $\mathrm{S}-\mathrm{N}$ fatigue characteristic within the high-cycle range the following conclusions can be formulated:

- the number of specimens used for tests affects the parameters of the obtained linear regression, which in turn affect the value of the fatigue life calculated using the estimated characteristic,

- small differences between the characteristics obtained with the aid of the methodology recommended in the PN standard (15 tests) and the ISO standard (30 tests) suggest that these curves are more accurate that the characteristic obtained using the EN guidelines (6 tests),

- $\quad$ performing more that 3 measurements at one load level leads to higher dispersion of results (lower value of the coefficient of determination was obtained),

- the largest differences between the obtained characteristics are observed at the ends of the examination ranges,

- the characteristic obtained using the IIW methodology [5] reveals that this methodology was inappropriate for the examined material and specimen geometry,

- guidelines of the EN standard [9] seem to be appropriate for preliminary examination, but they should be verified for other materials and specimen geometries, as well, as for other types of load, twisting for instance,

- although the EN standard [9] is not applicable to notched specimens, a suggestion that it can be used to construct the fatigue curve for such objects seems reasonable, which was confirmed by the experimental results,

- $\quad$ arguments in favour or the methodology contained in the EN document [9] include an unambiguous 
procedure of selecting intervals between load levels; this approach is also supported by the distributions of changes of the slope coefficient $\mathrm{m}$ presented in Fig. 5, Fig. 6, Fig. 7 and Fig. 8, as well as the analysis collated in Tab. 3,

- the use of load level intervals given in Tab. 3 when constructing fatigue characteristics for structural steels seems justified.

\section{BIBLIOGR APHY}

1. Kozak J., Górski Z., Fatigue strength determination of ship structural joints, Polish Maritime Research 2(69) Vol 18, 2011.

2. PN-EN 1993-1-9, Eurokod 3: Designing steel structures. Part 1-9: Fatigue, 2007 (in Polish).

3. Kocak M., et al.,. FITNET Fitness-for-Service PROCEDURE - FINAL DRAFT MK7. tom I: FITNET FFS Procedure. European Fitness-for-Service Thematic Network - FITNET, 2006.

4. Hobbacher A.F., The new IIW guidelines for fatigue assessment of welded joints and components- A comprehensive code recently updated. International Journal of Fatigue, Vol. 31, Is. 1, January 2009.

5. Hobbacher A, et al. Guidelines for fatigue design of welded joints and components, IIW document IIW-1823-07ex XIII-2151r4-07/XV-1254r4-07;2008.

6. ASTM E 739-91, Standard Practice for Statistical Analysis of Linear or Linearized Stress-Life $(S-N)$ and Strain-Life (S-N) Fatigue Data, 2004.

7. Data Sheet on Fatigue Properties of Rail Steel by Alternating Axial Loading Life Test. [online]. Meiji University Academic Frontier. [access: 07 August 2012]. World Wide Web: <http://www.isc.meiji.ac.jp/ shinrai/ H12/H12\%20 Alternating\%20Axial\%20(Rail\%20Steel2).pdf>.

8. Tomaszewski T., Sempruch J., Analysis of size effect in highcycle fatigue for EN AW-6063, Solid State Phenomena, Vol. $224,2015$.

9. PN-EN 3987, Aviation and astronautics - Methods to test metal materials - High-cycle fatigue tests with constant amplitude of controlled load, 2010 (in Polish).

10. PN-H 04325, Fatigue tests of metals - Basic terms and general guidelines on preparation of specimens and testing procedure,1976 (in Polish).

11. ISO 12107, Metallic materials - fatigue testing - statistical planning and analysis of data, 2003.
12. Skibicki D., Sempruch J., Pejkowski L., Steel X2CrNiMo17-12-2 testing for uniaxial, proportional and non-proportional loads as delivered and in the annealed condition, Material Science Forum, Vol. 726, 2012.

13. Sempruch J., Strzelecki P., Error of fatigue life determined according to the Fitnet method, 17th International Conference on Engineering Mechanics, Svratka, Czech Republic, May 2011.

14. Strzelecki P., Sempruch J., Experimental verification of analytical method for determining the S-N curve for alloy steel, Key Engineering Materials, Vol. 598, 2014.

15. Strzelecki P., Analytical method to determine high-cycle fatigue properties of materials and construction elements (in Polish), Ph.D. thesis, 2014.

16. Kenan G., Mehmet D., Mustafa U., Effect of cathodic polarisation on corrosion fatigue behaviour of ion nitrided AISI 4140 steel. International Journal of Fatigue, Vol. 24 Is. 5, May 2002.

17. Data Sheet on Fatigue Properties of SUJ2 Steel by Rotating Bending Test (HRC30),[online], Meiji University Academic Frontier, [access: 07 August 2012], World Wide Web: http:// www.isc.meiji.ac.jp/ shinrai/H01/H01\%20Rotating\%20 Bending\%20\%28SUJ-HRC30\%29.pdf.

18. Strzelecki P., Sempruch J., Analysing slope coefficient of the Wöhler curve within finite life range (in Polish). XXV Conference on Fatigue and Fracture Mechanics, BydgoszczFojutowo 2012.

19. Strzelecki P., Sempruch J., Hybrid method for determining fatigue characteristic in high cycle life. 20th International Conference Engineering Mechanics 2014, Svratka, Czech Republic, May 2014.

20. Strzelecki P., Sempruch J., Experimental verification of the analytical method for the estimated $S-N$ curve for limited fatigue life. Materials Science Forum, Fatigue Failure and Fracture Mechanics, Vol. 726, August 2012.

21. Sonsino S.M., 2007. Course of SN-curves especially in the high-cycle fatigue regime with regard to component design and safety. International Journal of Fatigue. Vol. 29, Is.12, December 2007. 


\title{
CONTACT WITH THE AUTHORS
}

\author{
Przemysław Strzelecki \\ Janusz Sempruch \\ Krzysztof Nowicki
}

UTP University of Science and Technology

ul. Ks. Kordeckiego 20

85-225 Bydgoszcz

Poland 